\title{
TU/e EmonOWEN

\section{Role of carbon atoms in the remote plasma deposition of hydrogenated amorphous carbon}

\section{Citation for published version (APA):}

Benedikt, J., Wisse, M., Woen, R. V., Engeln, R. A. H., \& Sanden, van de, M. C. M. (2003). Role of carbon atoms in the remote plasma deposition of hydrogenated amorphous carbon. Journal of Applied Physics, 94(10), 6932-6938. https://doi.org/10.1063/1.1622116

DOI:

$10.1063 / 1.1622116$

Document status and date:

Published: 01/01/2003

\section{Document Version:}

Publisher's PDF, also known as Version of Record (includes final page, issue and volume numbers)

\section{Please check the document version of this publication:}

- A submitted manuscript is the version of the article upon submission and before peer-review. There can be important differences between the submitted version and the official published version of record. People interested in the research are advised to contact the author for the final version of the publication, or visit the $\mathrm{DOI}$ to the publisher's website.

- The final author version and the galley proof are versions of the publication after peer review.

- The final published version features the final layout of the paper including the volume, issue and page numbers.

Link to publication

\section{General rights}

Copyright and moral rights for the publications made accessible in the public portal are retained by the authors and/or other copyright owners and it is a condition of accessing publications that users recognise and abide by the legal requirements associated with these rights.

- Users may download and print one copy of any publication from the public portal for the purpose of private study or research.

- You may not further distribute the material or use it for any profit-making activity or commercial gain

- You may freely distribute the URL identifying the publication in the public portal.

If the publication is distributed under the terms of Article 25fa of the Dutch Copyright Act, indicated by the "Taverne" license above, please follow below link for the End User Agreement:

www.tue.nl/taverne

Take down policy

If you believe that this document breaches copyright please contact us at:

openaccess@tue.nl

providing details and we will investigate your claim. 


\title{
Role of carbon atoms in the remote plasma deposition of hydrogenated amorphous carbon
}

\author{
J. Benedikt, ${ }^{\text {a) }}$ M. Wisse, ${ }^{\text {b) }}$ R. V. Woen, R. Engeln, and M. C. M. van de Sanden \\ Department of Applied Physics, Eindhoven University of Technology, P.O. Box 513, 5600 MB Eindhoven, \\ The Netherlands
}

(Received 3 April 2003; accepted 4 September 2003)

\begin{abstract}
The aim of this article is to determine the role of carbon atoms in the growth of hydrogenated amorphous carbon $(a-\mathrm{C}: \mathrm{H})$ films by means of an argon/acetylene expanding thermal plasma. Cavity ring down absorption spectroscopy is used to detect metastable carbon atoms by probing the $1 s^{2} 2 s^{2} 2 p 3 s^{1} P_{1} \leftarrow 1 s^{2} 2 s^{2} 2 p^{2}{ }^{1} S_{0}$ electronic transition. In addition to absorption measurements, the emission of the same transition is monitored by means of optical emission spectroscopy. These two measurements provide information about the local production of the $\mathrm{C}$ atoms and about their reactivity in the gas phase. It will be shown that under growth conditions in an $\mathrm{Ar} / \mathrm{C}_{2} \mathrm{H}_{2}$ expanding thermal plasma, the metastable carbon density is also representative for the ground state carbon density. From obtained results it is concluded that the carbon atoms react rapidly with acetylene in the gas phase and therefore their contribution to the growth of hard diamond-like $a-\mathrm{C}: \mathrm{H}$ films can be neglected. Only at low acetylene flows, the condition when soft polymer-like films are deposited, carbon atoms are detected close to the substrate and can possibly contribute to the film growth. (C) 2003 American Institute of Physics. [DOI: 10.1063/1.1622116]
\end{abstract}

\section{INTRODUCTION}

Carbon atoms are involved in various plasma-based processes. They play a role as intermediate in hydrocarbon flames, ${ }^{1}$ they are generated in chemical vapor deposition of diamond $^{2}$ and diamond-like carbon films. ${ }^{3}$ As a particle with four valence electrons it is very reactive in the gas phase (reaction rates with hydrocarbon molecules are on the order of $10^{-16} \mathrm{~m}^{3} \mathrm{~s}^{-1}$ ) and its sticking probability at the surface is expected to be close to unity. Carbon atoms can be produced by laser ablation, ${ }^{3}$ by noble gas ion bombardment ${ }^{4,5}$ of a graphite target or in the gas phase by electron impact dissociation of carbon containing molecules or radicals. It can also be a product of chemical reactions between radicals and molecules in the gas phase. Up to now several methods have been used to detect this atom: two photon absorption laser induced fluorescence, ${ }^{6-9}$ two photon induced excitation followed by spontaneous emission, ${ }^{1,10}$ laser induced fluorescence using vacuum ultraviolet excitation, ${ }^{11}$ multiphoton ionization $^{5,12}$ or (vacuum) ultraviolet absorption spectroscopy. ${ }^{2,13}$ In this article we will present an alternative way of measuring carbon atoms in their $1 s^{2} 2 s^{2} 2 p^{2}{ }^{1} S_{0}$ metastable state: cavity ring down absorption spectroscopy (CRDS). We combine these measurements with optical emission spectroscopy (OES) of the $1 s^{2} 2 s^{2} 2 p 3 s^{1} P_{1}^{0}$ $\rightarrow 1 s^{2} 2 s^{2} 2 p^{2}{ }^{1} S_{0}$ electronic transition.

At the Eindhoven University of Technology, remote expanding thermal plasmas (ETPs) are used for deposition of different kinds of films. ${ }^{14,15}$ Previous studies have shown that by injecting acetylene downstream into an expanding ther-

a) Author to whom correspondence should be addressed; electronic mail: j.benedikt@tue.nl

${ }^{b}$ Present address: Laser Center and Department of Physical Chemistry, Vrije Universiteit, De Boelelaan 1083, 1081 HV Amsterdam, The Netherlands. mal argon plasma, $a-\mathrm{C}: \mathrm{H}$ films of good quality can be deposited at a rate of up to $70 \mathrm{~nm} / \mathrm{s}$. Due to the adiabatic cooling, which takes place in the expansion, the electron temperature in the vessel is low $(<0.3 \mathrm{eV})^{16}$ and hence electron induced dissociation processes can be neglected. The combination of mass spectrometry and Langmuir probe measurements revealed the dominance of the argon ion induced dissociation of injected acetylene. ${ }^{17}$ The proposed mechanism for the plasma chemistry starts with a charge transfer reaction between an argon ion and an acetylene molecule ${ }^{18}$

$$
\mathrm{Ar}^{+}+\mathrm{C}_{2} \mathrm{H}_{2} \rightarrow \mathrm{Ar}+\mathrm{C}_{2} \mathrm{H}_{2}^{+}, *
$$

with a reaction rate of $k_{1} \approx 4.2 \times 10^{-16} \mathrm{~m}^{3} / \mathrm{s}$, which is followed by the dissociative recombination of the rovibrationally excited acetylene ion with an electron: ${ }^{19}$

$$
\begin{aligned}
\mathrm{C}_{2} \mathrm{H}_{2}^{+, *}+e^{-} & \rightarrow \mathrm{C}_{2} \mathrm{H}^{*}+\mathrm{H}^{*} \\
& \rightarrow \mathrm{C}_{2}^{*}+\mathrm{H}^{*}+\mathrm{H} \\
& \rightarrow \mathrm{CH}^{*}+\mathrm{CH}^{*},
\end{aligned}
$$

with a reaction rate in the order of $k_{2} \approx 3 \times 10^{-13} \mathrm{~m}^{3} / \mathrm{s}$. In the following, Reactions (1) and (2) will be referred to as primary reactions. It was argued ${ }^{20}$ that the $\mathrm{C}_{2} \mathrm{H}$ branch of reaction (2) is dominant. The production of $\mathrm{C}+\mathrm{CH}_{2}$ radicals in reaction (2) is energetically possible but highly improbable since, from a stereometric point of view, this radical needs major reorganization starting from $\mathrm{C}_{2} \mathrm{H}_{2}^{+}$and an electron. ${ }^{21}$ The products from reaction (2) can be dissociated again in a similar way using another argon ion and an electron. For the $\mathrm{C}_{2} \mathrm{H}$ radical:

$$
\begin{aligned}
\mathrm{Ar}^{+}+\mathrm{C}_{2} \mathrm{H}^{*} & \rightarrow \mathrm{Ar}+\mathrm{C}_{2} \mathrm{H}^{+, *}, \\
\mathrm{C}_{2} \mathrm{H}^{+, *}+e^{-} & \rightarrow \mathrm{C}_{2}^{*}+\mathrm{H}^{*} \\
& \rightarrow \mathrm{C}^{*}+\mathrm{CH}^{*} .
\end{aligned}
$$


These reactions will be called secondary reactions because a second argon ion and a second electron are needed. The carbon atoms together with the $\mathrm{CH}$ and $\mathrm{C}_{2}$ radicals are products of these secondary reactions. The reaction coefficients $k_{3}$ and $k_{4}$ of reactions (3) and (4) are not known, but they will probably have similar values as the reaction coefficients $k_{1}$ and $k_{2}$. In addition to these ion induced reactions, also reactions between acetylene and different radicals take place in the ETP as was already discussed by Benedikt $e t$ al. ${ }^{22}$

Due to the low electron temperature, the substrate selfbias is small $(<2 \mathrm{~V})$ and so ion bombardment is not involved in the deposition. At these conditions the film growth is governed by the flux of reactive (sticking) particles to the surface. The $\mathrm{C}, \mathrm{CH}$, and $\mathrm{C}_{2}$ radicals with expected high sticking probability can then play an important role during $a-\mathrm{C}: \mathrm{H}$ film growth. The $\mathrm{CH}$ (Engeln et al. ${ }^{23}$ ) and $\mathrm{C}_{2}$ radicals were already measured by means of CRDS in an $\mathrm{Ar} / \mathrm{C}_{2} \mathrm{H}_{2}$ ETP. Understanding the growth mechanism is particularly important in view of the fact that the high deposition rate of tens of nanometers per second does not compromise the film quality and still leads to $a-\mathrm{C}: \mathrm{H}$ films with hardness up to $14 \mathrm{GPa}$, mass density of $1.5-1.7 \mathrm{~g} / \mathrm{cm}^{3}$, spin density of $10^{20} \mathrm{~cm}^{-3}$, and good chemical stability and adhesion to the substrate. ${ }^{20,24}$

In this article we present the density measurement of carbon atoms in their $1 s^{2} 2 s^{2} 2 p^{21} S_{0}$ metastable state (further on called $\mathrm{C}^{*}$ ) by means of CRDS. These measurements are complemented with OES of the same electronic transition. On the basis of these measurements and involved plasma chemistry we will argue that $\mathrm{C}$ atoms, both in the ground state $\left(\mathrm{C}_{\mathrm{gr}}\right)$ as well as in excited states, are predominantly produced in secondary reactions (3) and (4). Once C atoms are produced they will react with acetylene and we will show that the reaction coefficient of this loss reaction is similar for both $\mathrm{C}^{*}$ and $\mathrm{C}_{\mathrm{gr}}$. In this case the $\mathrm{C}^{*}$ density scales with the $\mathrm{C}_{\mathrm{gr}}$ density. Finally we will conclude that carbon atoms can contribute to the growth of soft (hardness 4 $\mathrm{GPa}$ ), polymer-like $a-\mathrm{C}: \mathrm{H}$ films but they are not involved in the fast deposition of hard (14 GPa) $a-\mathrm{C}: \mathrm{H}$ films.

\section{EXPERIMENTAL SETUP}

The deposition setup is depicted in Fig. 1. The thermal argon plasma is produced in a so-called cascaded arc. The dc arc runs between three cathodes and the arc nozzle inside the channel (4 $\mathrm{mm}$ diameter) formed by a stack of four water cooled copper plates. The current setting (22-89 A) controls the ionization degree of the argon gas and therefore the flux of argon ions and electrons emanating from the cascaded arc. The typical arc power is in the range of $1-5 \mathrm{~kW}$ and a typical arc pressure is between 0.2 and 0.5 bar. The argon flow is kept constant at 100 sccs $\quad(1 \mathrm{sccs}=2.69$ $\times 10^{19}$ particles/s). The thermal argon plasma expands into a low-pressure vessel (typically $0.3 \mathrm{mbar}$ ) where first supersonic and, after a shock, subsonic expansion takes place. Due to high pressure difference between arc and the vessel, ETP is called a remote plasma; plasma creation is independent of the vessel conditions. ${ }^{14}$ Into the expanding plasma beam acetylene is injected by means of a gas injection ring. The

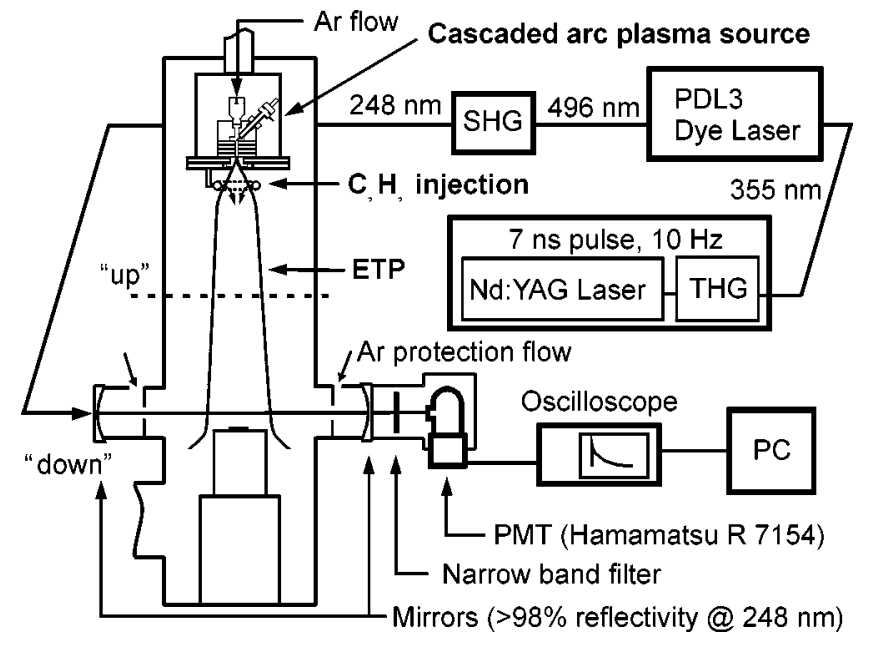

FIG. 1. Expanding thermal plasma deposition setup together with the CRDS setup.

acetylene flow is varied between 0 and 20 sccs. $a$-C:H films are deposited at a distance of $60 \mathrm{~cm}$ from the arc nozzle on a temperature controlled silicon substrate. No additional biasing is used at the substrate. For a more extensive treatment of the experimental setup the reader is referred to Gielen et al. ${ }^{20,24}$

Cavity ring down spectroscopy ${ }^{23,25}$ is used to detect $\mathrm{C}^{*}$ in the plasma. Measurements are performed at two different positions, one in the middle of the reactor, $0.25 \mathrm{~m}$ below the injection ring (called "up" position), and the other $0.52 \mathrm{~m}$ from the injection ring, $30 \mathrm{~mm}$ above the substrate (called "down" position). The required wavelength $(247.931 \mathrm{~nm})$ for absorption on $1 s^{2} 2 s^{2} 2 p 3 s^{1} P_{1} \leftarrow 1 s^{2} 2 s^{2} 2 p^{2}{ }^{1} S_{0}$ electronic transition (lowest carbon energy levels are shown in Fig. 2) is produced by a Nd:YAG pumped dye laser (Spectra Physics DCR11/PDL3 combination) using Coumarin 500 and frequency doubling of the output in a Beta-barium borate crystal. The laser pulse is $7-10 \mathrm{~ns}$ long with a repetition rate of $10 \mathrm{~Hz}$ and a spectral bandwidth of about $0.08 \mathrm{~cm}^{-1}$. Two high reflectivity mirrors (Laseroptik, $\varnothing 25 \times 6.5 \mathrm{~mm}$, planconcave, $r=-1000 \mathrm{~mm}$ ) form an optical cavity. An argon protection flow of $6 \mathrm{sccs}$ flows between each mirror and the reactor to protect them during plasma operation. The re-

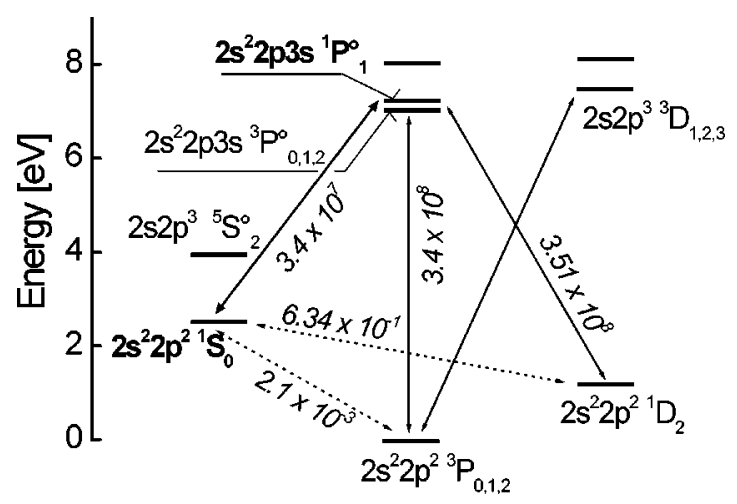

FIG. 2. Energy level diagram of the carbon atom. The lower and upper level of the transition used in this article are in bold. Einstein coefficients (in $\mathrm{s}^{-1}$ ) are also included (in italic). 
flectivity of the mirrors is between 0.988 and 0.992 , which results in a ring down time in the range from 230 to $350 \mathrm{~ns}$. The light leaking out of the cavity is detected by a photomultiplier tube (Hamamatsu R7154) connected to an oscilloscope (Tektronix TDS 340A, 8 bit, $350 \mathrm{MHz}$ bandwidth, 500 Msamples/s). A filter in front of the photomultiplier tube blocks the emission from the plasma. A LABVIEW program controls the tuning of the dye laser and reads out the recorded transients via a general purpose interface bus interface. At each frequency typically 32 transients are averaged on the on-board 16-bit memory of the oscilloscope. The averaged transient, read out by the PC, is fitted with a standard least-squares fitting routine to an exponentially decaying function.

The decay time $\tau$ of the transient, can be written as

$$
\tau(\nu)=\frac{d}{c\left(\ln R_{\mathrm{eff}}+A\right)}=\frac{d}{c\left(\ln R_{\mathrm{eff}}+\sigma(\nu) \int_{0}^{d} n(x) d x\right)},
$$

where $d$ is the cavity length, $c$ is the light speed, $R_{\text {eff }}$ is the effective mirror reflectivity, $\sigma(\nu)$ is the frequency-dependent cross section of the absorbing species, $\int_{0}^{d} n(x) d x$ is the lineintegrated number density, and $A$ is absorption per pass in the cavity. The value of $A$ can be easily calculated when the ring down times $\tau_{0}$ of the empty cavity and $\tau$ of the cavity with absorbing species are known:

$$
A=\frac{d}{c}\left(\frac{1}{\tau}-\frac{1}{\tau_{0}}\right)
$$

We assumed the density $n$ to be constant over the length $L$ $<d$ in the expanding plasma and zero elsewhere. The effective path length $L$ is assumed (based on Langmuir probe measurements of the electron density profile of pure argon plasma at up position) to be $0.05 \mathrm{~m}, 0.09$ and $0.10 \mathrm{~m}$ at the arc currents 22, 48, and $61 \mathrm{~A}$, respectively. The same lengths $L$ are used for the up and down position. However it is expected that at the down position the expanding beam is broader and hence the calculated density can be slightly overestimated. The metastable carbon number density was calculated from the area under the absorption peak, obtained by performing a wavelength scan around the transition resonance frequency. The absorption measurement was reproducible within $4 \%$ relative error for the down position. The up measurements which were done later, displayed shorter ring down times ( $\sim 100 \mathrm{~ns}$, result of deterioration of the mirrors), resulting in a slight increase of the noise level. Because of the uncertainty in the Einstein coefficient ${ }^{26}$ (about 10\%) and the uncertainty of the real absorption path length we estimate that the calculated density is correct within $30 \%$, which comprises both the systematic and random errors.

It is very important to ensure that there is no saturation of the transition during the measurement. A way to verify this is to calculate the saturation parameter $S=P / R$, where- $P$ stands for the pumping rate to the upper state, which can be approximated by $P=B_{i j} \cdot \rho(\nu)$ and $R$ is the relaxation rate of the transition $i j$, which contains the various possible relaxation processes (radiative or collisional) of the upper and

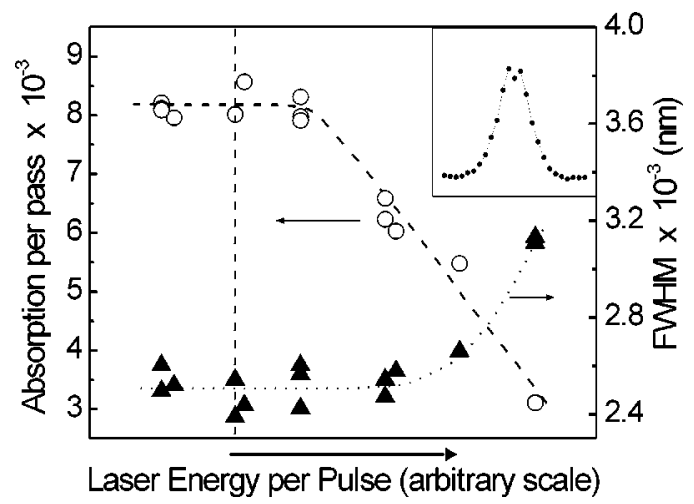

FIG. 3. Height of absorption peak and full peak width at half maximum (FWHM) as a function of the laser spectral energy density in the cavity. The $x$-axis scale is not calibrated and is used only for comparison. Dotted lines are drawn to guide the eye.

lower levels. ${ }^{27} B_{i j}$ is the Einstein absorption coefficient for the transition $i \rightarrow j$ and $\rho(\nu)$ is energy density of the laser light in the cavity.

Since the laser energy going into the cavity is small and we are not able to measure it exactly, we can only estimate the value of the energy density inside the cavity. Furthermore, not all values of the relaxation processes are known. Taking into account the uncertainties mentioned above, our estimation of the saturation parameter was close to unity, which already could indicate saturation effects. Therefore, we investigated in detail the effect of increased laser energy per pulse on the absorption peak. In Fig. 3 the absorption per pass and the full width at the half maximum of the carbon metastable absorption peaks are shown as a function of the laser energy per pulse. The experimental conditions were $I_{\text {arc }}=48 \mathrm{~A}, \Phi(\mathrm{Ar})=100 \mathrm{sccs}$, and $\Phi\left(\mathrm{C}_{2} \mathrm{H}_{2}\right)=1.7 \mathrm{sccs}$. The energy scale is only for reference and is not calibrated. Estimated values of energy per pulse range from less than $1 \mathrm{~nJ}$ on the left side to hundreds of $\mathrm{nJ}$ on the right side of the $x$ axis. Because the laser spectral width is smaller than the peak width, inhomogeneous saturation can occur. With low laser energy per pulse the absorption and full width half maximum (FWHM) are constant. As the energy per pulse increases, the absorption is reduced due to saturation, but the FWHM of the peaks remains unaffected. As the energy per pulse rises even more, the absorption peak starts to broaden. At the highest energy, a Lamb dip is observed (see insert in Fig. 3).

The problem of inhomogeneous saturation in CRDS spectroscopy was recently studied in detail by Macko et al. ${ }^{28}$ and was sufficiently explained by their model. Although their model could be adjusted for our situation, for our measurements it suffices to be sure that saturation does not occur. The vertical dashed line in Fig. 3 indicates the laser energy per pulse at which all our CRDS measurements were performed. The laser energy is far from causing saturation, but it is still high enough to provide a good signal to noise ratio.

OES measurements of the $1 s^{2} 2 s^{2} 2 p^{2}{ }^{1} S_{0}$ $\rightarrow 1 s^{2} 2 s^{2} 2 p 3 s^{1} P_{1}^{0}$ emission are performed with a fiber optic spectrometer (Ocean Optics USB2000). It is an easy to 

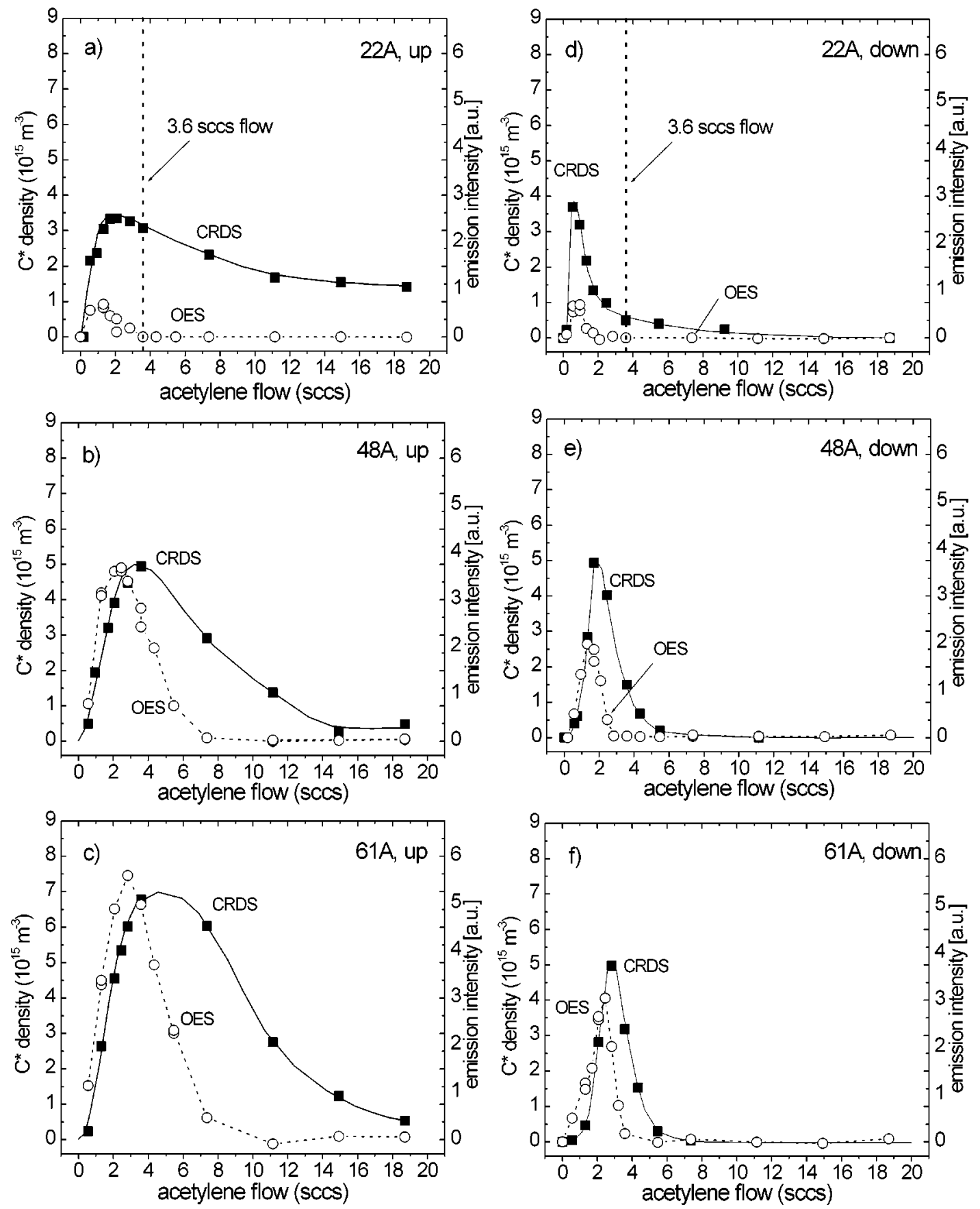

FIG. 4. Measured $\mathrm{C}^{*}$ density together with emission intensity. The measurements are done at up and down position, at three different currents and as a function of acetylene flow.

operate plug and play apparatus which is able to record emission spectra from 190 to $850 \mathrm{~nm}$. The spectral resolution is about $1 \mathrm{~nm}$. The light was collected over a solid angle of $5.5 \times 10^{-4} \mathrm{srad}$, at a position $0.39 \mathrm{~m}$ from the expanding plasma axis without any imaging optics, in order to enhance signal intensity, giving $37 \mathrm{~mm}$ spatial resolution at the beam axis. The emission was observed through a quartz window and measurements were done both at up and down position and under the same conditions as the CRDS measurements. Also the argon backflow through the CRDS mirrors was used in order to maintain the same pressure in the reactor. The emission peak is well resolved without overlapping other emission features. The area under the peak is taken as a measure of emission intensity.

\section{RESULTS AND DISCUSSION}

\section{A. Plasma chemistry of the carbon metastable state}

Figure 4 shows the results of the CRDS absorption measurements together with the results of the OES measurements. The results are shown for two different positions, up and down, for three different currents 22,48 , and $61 \mathrm{~A}$ and as a function of acetylene flow. In all cases the measured data have a maximum at low acetylene flows, when the ratio of 
$\mathrm{C}_{2} \mathrm{H}_{2}$ flow and argon ion and electron flow into the reactor is small. This corroborates the assumption that $\mathrm{C}$ atoms are mainly created in secondary reactions (3) and (4). To create $\mathrm{C}$ atoms in these reactions two Ar ions and electrons are needed per acetylene molecule. Hence maximum absorption should occur approximately at an acetylene flow equal to half the argon ion and electron flow emanating from the arc. The magnitude of the measured maxima in density and intensity increases with increasing arc current as a result of higher argon ion and electron flow from the cascaded arc at higher arc currents. Maximal $\mathrm{C}^{*}$ density of $7 \times 10^{15} \mathrm{~m}^{-3}$ is measured at the up position at an arc current of $61 \mathrm{~A}$.

Both CRDS and OES measurements show that the carbon atom can be produced internally excited. In the subsequent reactions (1)-(4) the recombination energy of two argon ions is available $(2 \times 15.76=31.52 \mathrm{eV})$. Part of this energy is used for breaking the $\mathrm{C}-\mathrm{H}(\sim 5.6 \mathrm{eV})$ and $\mathrm{C} \equiv \mathrm{C}$ $(\sim 10 \mathrm{eV})$ bonds. $^{29}$ This leaves approximately $16 \mathrm{eV}$ for the $\mathrm{C}+\mathrm{CH}$ produced in one of the two branches of the secondary reaction (4) and which is enough to produce carbon atoms in different excited states. Even in the case, that a hydrogen atom created in primary reaction (2) is excited with its electron in the $n=2$ state $(10.15 \mathrm{eV})$, the remaining energy $(\sim 5.8 \mathrm{eV})$ is large enough to produce a carbon atom in its ${ }^{1} S_{0}$ metastable state. The carbon emission is the evidence that at least a fraction of $\mathrm{C}_{2} \mathrm{H}$ from primary reaction (2) is highly rovibrationally excited.

It is clear from Fig. 4 that there is a difference between the results of CRDS and OES measurements. This is due to different radiative lifetimes of the upper and lower level of the probed transition. CRDS measures the ${ }^{1} S_{0}$ metastable state, which has a long radiative lifetime $(\sim 1.58 \mathrm{~s})$ compared to the upper ${ }^{1} P_{1}^{0}$ level of the transition. The density of the ${ }^{1} S_{0}$ metastable state will not be depleted by radiative deexcitation and will be determined only by chemical reactions, diffusion, and convection of $\mathrm{C}^{*}$ atoms in the plasma. On the contrary the upper state ${ }^{1} P_{1}^{0}$ has a very short radiative lifetime $(\sim 2.6 \mathrm{~ns})$ which will result in a very fast deexcitation to the lower levels. The density of this upper state is then determined by local production of excited carbon in the plasma and loss by radiative processes. Considering these aspects the OES intensity is a measure of the local production rate of (excited) carbon atoms in the secondary reaction (4).

As seen in Fig. 4 carbon emission appears only at low acetylene flows when the $\mathrm{C}_{2} \mathrm{H}_{2}$ flow/ $\left(\mathrm{Ar}^{+}, e^{-}\right)$flow ratio is small. At high acetylene flows, argon ions, and electrons are depleted very fast in reactions (1)-(4). Then, even at the up position, which is close to the injection ring, no argon ions and electrons are available for the secondary reactions (3)(4) and the carbon atom production stops. At low acetylene flows, when more than one argon ion and electron pair is available per acetylene molecule, argon ions and electrons can reach the substrate and carbon emission is measured even at the down position. Carbon emission also indicates that the $\mathrm{C}_{2} \mathrm{H}$ radical is present in the region close to the substrate at low acetylene flows.

As was already explained, CRDS measures the $\mathrm{C}^{*}$ atom density, which is determined by the production and loss of these atoms in chemical reactions. The $\mathrm{C}^{*}$ density depends critically on the distance from the injection ring. At the up position $\mathrm{C}^{*}$ is detected in all conditions, even at high acetylene flows. The reason is that the dissociation of acetylene in the primary reactions (1) and (2) takes place close to the injection ring, producing the $\mathrm{C}_{2} \mathrm{H}$ radical, a precursor for $\mathrm{C}$ atom production. Moreover the argon ion and electron densities are still high enough and so there will always be a small fraction of argon ions and electrons used in secondary reactions (3) and (4), even at high acetylene flows. As the plasma flows towards the substrate, carbon atoms can react further with acetylene: ${ }^{30}$

$$
\mathrm{C}+\mathrm{C}_{2} \mathrm{H}_{2} \rightarrow \mathrm{C}_{3} \mathrm{H}+\mathrm{H}
$$

and its density along the expansion axis will decrease. At high acetylene flows, higher than the argon ion and electron flow, carbon atoms react away and the $\mathrm{C}^{*}$ density at the down position is below the detection limit of the CRDS technique $\left(\sim 1 \times 10^{14} \mathrm{~m}^{-3}\right)$. Also argon ions and electrons in the expansion are depleted faster at high acetylene flows and thus the carbon production is confined to a region closer to the injection ring than at low acetylene flows. At low $\mathrm{C}_{2} \mathrm{H}_{2} /\left(\mathrm{Ar}^{+}, e^{-}\right)$ratio, most of the $\mathrm{C}_{2} \mathrm{H}_{2}$ is consumed in primary reactions (1) and (2) and hence reactions (7) can be neglected. At these conditions the $\mathrm{C}^{*}$ can reach (or even be produced, see OES measurement) close to the substrate as shown by the CRDS measurements performed in down position at all arc currents. The reaction rate for reaction (7) was measured at room temperature and for $\mathrm{C}_{\mathrm{gr}}$ atoms and its value is $k_{5} \approx 2.8 \times 10^{-16} \mathrm{~m}^{3} / \mathrm{s}$. Other measurements and theoretical calculations ${ }^{31,32}$ of $k_{5}$ reveal a weak temperature dependence, all the reported values being between $2 \times 10^{-16}$ and $3.7 \times 10^{-16} \mathrm{~m}^{3} \mathrm{~s}^{-1}$. Still the value of reaction rate for reaction (7) involving $\mathrm{C}^{*}$ instead of $\mathrm{C}_{\mathrm{gr}}$ can be different from reported values. The value of $k_{5}^{*}$ can be estimated using the CRDS density measurements done at an arc current of $22 \mathrm{~A}$ and with an acetylene flow of $3.6 \mathrm{sccs}$. $\mathrm{C}^{*}$ atoms production between up and down position with this acetylene flow can be neglected since emission is below the detection limit. From the mass spectrometry measurement of acetylene consumption we know ${ }^{22}$ that approximately $2.4 \operatorname{sccs}(2 / 3$ of the acetylene flow) is not consumed at these conditions. Assuming a beam area of $0.0025 \mathrm{~m}^{2}$ (diameter $0.05 \mathrm{~m}$ ) and directed velocity of $1000 \mathrm{~m} / \mathrm{s}$ the acetylene density in the beam is approximately $3.3 \times 10^{19} \mathrm{~m}^{-3}$. An exponential decay of the $\mathrm{C}^{*}$ density due to reactions with acetylene (assuming constant acetylene density) during the time necessary for transport from the up position to down position $(\Delta z / v$ $\sim 0.27 / 1000=0.27 \mathrm{~ms}$ ) gives an estimate of the reaction rate $k_{5}^{*}$ :

$$
k_{5}^{*}=\frac{\ln \left(\frac{n_{\text {up }}}{n_{\text {down }}}\right)}{t_{\text {transport }} \cdot n_{\mathrm{C}_{2} \mathrm{H}_{2}}}=2 \times 10^{-16} \mathrm{~m}^{3} / \mathrm{s},
$$

where we used the measured value of approximately 5.2 for the ratio of the $\mathrm{C}^{*}$ density up and down. The estimated value of $2 \times 10^{-16} \mathrm{~m}^{3} / \mathrm{s}$ is in very good agreement with the range of $k_{5}$ values reported in the literature. Considering the fact 
that the $\mathrm{C}^{*}$ density measured at the down position is probably slightly underestimated even better agreement is reached.

\section{B. The importance of the carbon atoms for a-C:H growth}

The important question to be addressed is to what extend the measured $\mathrm{C}^{*}$ density is representative for the $\mathrm{C}_{\mathrm{gr}}$ atoms. During their creation, carbon atoms gain a high excitation energy because of the redistribution of the energy of the reactants over the products. Since the lifetime of the metastable state $(1.5 \mathrm{~s})$ is longer than the residence time of the particles in the vessel (typically $400 \mathrm{~ms}$ ) thermal equilibrium between $\mathrm{C}^{*}$ and $\mathrm{C}_{\mathrm{gr}}$ atoms cannot be assumed. If the Boltzman equation is used to calculate the ground state density, assuming a gas temperature of $2000 \mathrm{~K}$, the resulting flow of carbon atoms towards the substrate is at least 2 orders of magnitude higher than the maximum possible carbon flow calculated on the basis of the amount of injected acetylene.

So the remaining question is whether the ratio $\mathrm{C}^{*} / \mathrm{C}_{\mathrm{gr}}$ is constant. The discussion can be based on a simple model describing the plasma chemistry. In this model, the complex expansion is treated as a cylinder in which all the species move with the same drift velocity from the injection ring towards the substrate. In this way diffusion is neglected in radial direction. This is feasible since the radial diffusion times of different species were calculated ${ }^{33}$ to be typically 10 ms or higher, which is at least ten times slower than the transport time from the nozzle to the substrate $(\sim 1 \mathrm{~ms})$. In axial direction the convection $(1000 \mathrm{~m} / \mathrm{s}$ drift velocity) is much larger than diffusion. When the drift velocity is assumed to be constant along the expansion axis (which is reasonable approximation for the subsonic part of the ETP, i.e., after the stationary shock wave ${ }^{16}$ ) and only reactions (4) and (5) are considered as production and loss terms, the density evolution of $\mathrm{C}_{\mathrm{gr}}$ and $\mathrm{C}^{*}$ along the expansion axis can be described by the following differential equations:

$$
\begin{gathered}
\nu \frac{d}{d z}\left[\mathrm{C}_{\mathrm{gr}}\right]_{z}=k_{4} \cdot\left[e^{-}\right]_{z} \cdot\left[\mathrm{C}_{2} \mathrm{H}^{+}\right]_{z}-k_{5} \cdot\left[\mathrm{C}_{\mathrm{gr}}\right]_{z} \cdot\left[\mathrm{C}_{2} \mathrm{H}_{2}\right]_{z}, \\
\nu \frac{d}{d z}\left[\mathrm{C}^{*}\right]_{z}=k_{4}^{*} \cdot\left[e^{-}\right]_{z} \cdot\left[\mathrm{C}_{2} \mathrm{H}^{+}\right]_{z}-k_{5}^{*} \cdot\left[\mathrm{C}^{*}\right]_{z} \cdot\left[\mathrm{C}_{2} \mathrm{H}_{2}\right]_{z},
\end{gathered}
$$

where $[X]_{z}$ means density of species $X$ at the distance $z$ from the injection ring. The metastable state is representative for the ground state if the following condition is fulfilled:

$$
\text { const }=\frac{\left[\mathrm{C}^{*}\right]_{z}}{\left[\mathrm{C}_{\mathrm{gr}}\right]_{z}}=\frac{\left[\mathrm{C}^{*}\right]_{z+d z}}{\left[\mathrm{C}_{\mathrm{gr}}\right]_{z+d z}}=\frac{\left[\mathrm{C}^{*}\right]_{z}+\nu \frac{d}{d z}\left[\mathrm{C}^{*}\right]_{z}}{\left[\mathrm{C}_{\mathrm{gr}}\right]_{z}+\nu \frac{d}{d z}\left[\mathrm{C}_{\mathrm{gr}}\right]_{z}}
$$

which gives, after substituting $\left[\mathrm{C}^{*}\right]_{z}=$ const $\cdot\left[\mathrm{C}_{\mathrm{gr}}\right]_{z}$ on the right hand side, the condition:

$$
\frac{\nu \frac{d}{d z}\left[\mathrm{C}^{*}\right]_{z}}{\nu \frac{d}{d z}\left[\mathrm{C}_{\mathrm{gr}}\right]_{z}}=\frac{(5)}{(4)}=\text { const. }
$$

First we can determine whether this condition is valid when only production [reaction (4)] is taken into account. In this case Eqs. (4) and (5) do not depend on $\mathrm{C}_{\mathrm{gr}}$ or $\mathrm{C}^{*}$ densities, respectively, and their ratio $(5) /(4)$ is constant and has a value of $k_{4}^{*} / k_{4}$. The density at the up position is more determined by $\mathrm{C}$ production, so the $\mathrm{C}^{*}$ density should be proportional to the $\mathrm{C}_{\mathrm{gr}}$ density.

If the loss reaction (7) is also taken into account, Eq. (12) is constant only if reaction rates $k_{5}$ and $k_{5}^{*}$ are equal. Then the $\mathrm{C}^{*}$ density scales with the $\mathrm{C}_{\mathrm{gr}}$ density. Even with additional loss terms taken into account, the $\mathrm{C}^{*}$ density can still scale with the $\mathrm{C}_{\mathrm{gr}}$ density, provided that the reaction rates for these loss reactions are again the same for $\mathrm{C}^{*}$ and $\mathrm{C}_{\mathrm{gr}}$. We have already shown before that the reaction rate of $\mathrm{C}^{*}$ with acetylene is in the range of reported values for $\mathrm{C}_{\mathrm{gr}}$ which leads us to the conclusion, assuming that the main loss process of $\mathrm{C}$ atoms in the plasma is in reaction with $\mathrm{C}_{2} \mathrm{H}_{2}$, that the $\mathrm{C}^{*}$ density measured in the $\mathrm{Ar} / \mathrm{C}_{2} \mathrm{H}_{2}$ ETP is also representative for the $\mathrm{C}_{\mathrm{gr}}$ density and their ratio $\mathrm{C}^{*} / \mathrm{C}_{\mathrm{gr}}$ is equal to $k_{4}^{*} / k_{4}$ ratio. Since we do not know this ratio, we can only estimate its lowest value. At Fig. 4(c) the maximal measured $\mathrm{C}^{*}$ density $7 \times 10^{15} \mathrm{~m}^{-3}$ is at the acetylene flow of 4 sccs. In the case of complete decomposition of injected $\mathrm{C}_{2} \mathrm{H}_{2}$ the highest $\mathrm{C}_{\mathrm{gr}}$ density at these conditions, taking 1000 $\mathrm{m} / \mathrm{s}$ the drift velocity and $0.1 \mathrm{~m}$ the beam diameter, can be $2 \times 10^{19} \mathrm{~m}^{-3}$ [which is really the upper estimate, since complete decomposition of injected acetylene is quite unlikely and also $\mathrm{C}_{2}\left(\sim 10^{17} \mathrm{~m}^{-3}\right)$ and $\mathrm{CH}\left(\sim 8 \times 10^{16} \mathrm{~m}^{-3}\right)$ radicals were detected and the $\mathrm{C}_{2} \mathrm{H}$ radicals and $\mathrm{C}_{2} \mathrm{H}_{2}$ molecules are also present in the plasma at these conditions]. This density gives the lowest possible $k_{4}^{*} / k_{4}$ ratio of $2.5 \times 10^{-4}$, with $1 \times 10^{-3}$ being a more realistic estimate. Then from the down measurements we know that at high acetylene flows [high $\mathrm{C}_{2} \mathrm{H}_{2}$ flow/ $\left(\mathrm{Ar}^{+}, e^{-}\right)$flow ratio] metastable carbon absorption close to the substrate is below the detection limit of CRDS $\left(\sim 1 \times 10^{14} \mathrm{~m}^{-3}\right)$ giving the upper estimate for $\mathrm{C}_{\mathrm{gr}}$ density to be $1 \times 10^{17} \mathrm{~m}^{-3}$ and maximum carbon atom flux towards the surface to be $1 \times 10^{20}$ atoms s${ }^{-1} \mathrm{~m}^{-2}$. From the growth rate and film density we know that the flux of $2.5 \times 10^{21}$ atoms s${ }^{-1} \mathrm{~m}^{-2}$ is necessary to maintain a high deposition rate and therefore we can assume that carbon contribution to the growth of hard diamond-like film is negligible. In contrast, at low $\mathrm{C}_{2} \mathrm{H}_{2}$ flows [small $\mathrm{C}_{2} \mathrm{H}_{2}$ flow/ $\left(\mathrm{Ar}^{+}, e^{-}\right)$flow ratio] $\mathrm{C}$ atoms are present above the substrate and a significant contribution to the growth cannot be excluded.

Even in the case of $k_{5}^{*}$ being different from $k_{5}$, or in the case that the $\mathrm{C}$ atoms are also lost in reactions with other species (e.g., $\mathrm{C}_{4} \mathrm{H}_{2}$ or $\mathrm{C}_{6} \mathrm{H}_{2}$ ) and the $\mathrm{C}^{*}$ absorption is no 
longer representative for $\mathrm{C}_{\mathrm{gr}}$, we have still enough information to predict the $\mathrm{C}_{\mathrm{gr}}$ density in the plasma close to the substrate. The OES measurements at the up position show that at high acetylene flows the $\mathrm{C}_{\mathrm{gr}}$ production is negligible, which means that $\mathrm{C}_{\mathrm{gr}}$ on its way down can only be lost, e.g., in reaction (5) with abundant acetylene. Its density will then rapidly decrease, the faster the more acetylene is injected into the vessel at a fixed arc current. In this case the role of carbon atoms during the growth under high acetylene flow conditions, when high deposition rates and good mechanical properties of $a-\mathrm{C}: \mathrm{H}$ films are reached, is negligible. At low acetylene flows, when films are more soft and polymer-like, $\mathrm{C}^{*}$ (and also $\mathrm{C}_{\mathrm{gr}}$ ) atoms are present in the region close to the substrate (with the $\mathrm{C}^{*}$ densities as high as $5 \times 10^{15} \mathrm{~m}^{-3}$ ), and they can influence and contribute to the film growth. This result fully corroborates our previous findings about plasma chemistry and about the growth mechanism of hard $a$-C:H films without application of substrate bias, in which secondary reaction products $\left(\mathrm{C}, \mathrm{CH}\right.$, and $\mathrm{C}_{2}$ radicals) play only a minor role. ${ }^{22}$ The most probable growth precursors for the growth then remain the $\mathrm{C}_{2} \mathrm{H}$ radical, primary reaction product, and probably also the rovibrationally excited $\mathrm{C}_{4} \mathrm{H}_{2}$ molecule, the product of reaction of the $\mathrm{C}_{2} \mathrm{H}$ radical, and acetylene. ${ }^{22}$ This may suggest that in the absence of ion bombardment the contribution of unsaturated hydrocarbon radicals such as $\mathrm{C}_{2} \mathrm{H}$ is a prerequisite for hard $a-\mathrm{C}: \mathrm{H}$ films. Similar findings were reported by Jacob. ${ }^{34}$

\section{CONCLUSIONS}

We measured the $1 s^{2} 2 s^{2} 2 p 3 s^{1} P_{1} \leftrightarrow 1 s^{2} 2 s^{2} 2 p^{2}{ }^{1} S_{0}$ electronic transition of atomic carbon both in absorption (CRDS) and emission (OES). The measurements were done for three different arc currents and as a function of acetylene flow in $\mathrm{Ar} / \mathrm{C}_{2} \mathrm{H}_{2}$ expanding thermal plasma. Two positions $0.25 \mathrm{~m}$ and 0.52 from the $\mathrm{C}_{2} \mathrm{H}_{2}$ injection nozzle were chosen in order to study plasma chemistry development in the ETP plasma. The latter position was $0.03 \mathrm{~m}$ above the substrate. All the results show intensity maxima at low acetylene flows, where the $\mathrm{C}_{2} \mathrm{H}_{2}$ flow/ $\left(\mathrm{Ar}^{+}, e^{-}\right)$flow ratio is smaller then unity. Based on these results the reaction mechanism involving two argon ions per one $\mathrm{C}_{2} \mathrm{H}_{2}$ molecule was suggested as a dominant source for (internally excited) carbon atom production. The decrease of $\mathrm{C}^{*}$ density between the up and down position can be attributed to the loss reaction of $\mathrm{C}^{*}$ with acetylene. The estimated reaction coefficient is in good agreement with the known reaction coefficient for the reaction of $\mathrm{C}_{\mathrm{gr}}$ with acetylene. In this case, assuming also that all other possible loss reactions of carbon atoms have similar reaction coefficients for $\mathrm{C}^{*}$ and $\mathrm{C}_{\mathrm{gr}}$, the $\mathrm{C}^{*}$ absorption is also a measure for the $\mathrm{C}_{\mathrm{gr}}$ density. But, even in the case where the loss process for $\mathrm{C}^{*}$ is different than for $\mathrm{C}_{\mathrm{gr}}$, the conclusion can be drawn that the carbon atom contribution to the $a-\mathrm{C}: \mathrm{H}$ film growth is only significant at small acetylene flows, when the ratio $\mathrm{C}_{2} \mathrm{H}_{2}$ flow/ $\left(\mathrm{Ar}^{+}, e^{-}\right)$flow is on the order of or smaller than unity. For high acetylene flows carbon atoms are lost in the gas phase in reaction with acetylene and their role during $a-\mathrm{C}: \mathrm{H}$ film growth is negligible.

\section{ACKNOWLEDGMENTS}

The authors would like to thank M. J. F. van de Sande, J. F. C. Jansen, A. B. M. Hüskens, and H. M. M. de Jong for their skillful technical assistance and S. Agarwal for his contribution to the experimental work. This work is part of the research program of the "Stichting voor Fundamenteel Onderzoek der Materie" (FOM) and was done in the frame of NATO Science for Peace Project No. 974354.

${ }^{1}$ M. Alden, P.-E. Bengtsson, and U. Westblom, Opt. Commun. 71, 263 (1989).

${ }^{2}$ H. Ito, K. Teii, M. Ishikawa, M. Ito, M. Hori, T. Takeo, T. Kato, and T. Goto, Jpn. J. Appl. Phys., Part 1 38, 4504 (1999).

${ }^{3}$ S. J. P. Laube and A. A. Voevodin, Surf. Coat. Technol. 105, 125 (1998).

${ }^{4}$ M. Röwekamp, A. Goehlich, and H. F. Döbele, Appl. Phys. A: Solids Surf. 54, 61 (1992).

${ }^{5}$ A. Goehlich, A. Goehlich, and H. F. Döbele, Nucl. Instrum. Methods Phys. Res. B 164-165, 827 (2000).

${ }^{6}$ P. Das, G. Ondrey, N. van Veen, and R. Bersohn, J. Chem. Phys. 79, 724 (1983).

${ }^{7}$ K. H. Becker, K. J. Brockman, and P. Wiesen, J. Chem. Soc., Faraday Trans. 2 84, 455 (1998).

${ }^{8}$ U. Westblom, P.-E. Bengtsson, and M. Alden, Appl. Phys. B: Photophys. Laser Chem. 52, 371 (1991).

${ }^{9}$ T. R. O’Brian and J. E. Lawler, J. Quant. Spectrosc. Radiat. Transf. 57, 309 (1996).

${ }^{10}$ H. Bergström, H. Hallstadius, H. Lundberg, and A. Persson, Chem. Phys. Lett. 155, 27 (1989)

${ }^{11} \mathrm{Ph}$. Mertens and P. Bogen, Appl. Phys. A: Solids Surf. 43, 197 (1987).

${ }^{12}$ P. J. H. Tjossem and K. C. Smyth, Chem. Phys. Lett. 144, 51 (1987).

${ }^{13}$ H. Ito, M. Ikeda, M. Ito, M. Hori, T. Takeo, H. Hattori, and T. Goto, Jpn. J. Appl. Phys., Part 2 36, L880 (1997).

${ }^{14}$ M. C. M. van de Sanden, R. J. Severens, W. M. M. Kessels, R. F. G. Meulenbroeks, and D. C. Schram, J. Appl. Phys. 84, 2426 (1998).

${ }^{15}$ R. Groenen, J. Loffler, P. M. Sommeling, J. L. Linden, E. A. G. Hamers, and R. E. I. Schropp, Thin Solid Films 392, 315 (2001).

${ }^{16}$ M. C. M. van de Sanden, J. M. de Regt, and D. C. Schram, Plasma Sources Sci. Technol. 3, 511 (1994).

${ }^{17}$ A. de Graaf, M. F. A. M. van Hest, M. C. M. van de Sanden, K. G. Y. Letourneur, and D. C. Schram, Appl. Phys. Lett. 74, 2927 (1999).

${ }^{18}$ M. Tsuji, H. Kouno, K. Matsumura, T. Funatsu, and Y. Nishimura, J. Chem. Phys. 98, 2011 (1993).

${ }^{19}$ P. M. Mul and J. W. McGowan, Astrophys. J. 237, 749 (1980).

${ }^{20}$ J. W. A. M. Gielen, M. C. M. van de Sanden, P. R. M. Kleuskens, and D. C. Schram, Plasma Sources Sci. Technol. 5, 492 (1996).

${ }^{21}$ E. Herbst, Astrophys. J. 222, 508 (1978).

${ }^{22}$ J. Benedikt, R. V. Woen, S. L. M. van Mensfoort, V. Perina, J. Hong, and M. C. M. van de Sanden, Diamond Relat. Mater. 12, 90 (2003).

${ }^{23}$ R. Engeln, K. G. Y. Letourneur, M. G. H. Boogaarts, M. C. M. van de Sanden, and D. C. Schram, Chem. Phys. Lett. 310, 405 (1999).

${ }^{24}$ J. W. A. M. Gielen, W. M. M. Kessels, M. C. M. van de Sanden, and D. C. Schram, J. Appl. Phys. 82, 2643 (1997).

${ }^{25}$ K. W. Busch and M. A. Busch, Cavity-Ringdown Spectroscopy (American Chemical Society, Washington, D.C., 1999).

${ }^{26}$ W. L. Wiese, J. R. Fuhr, and T. M. Deters, Atomic Transition Probabilities of Carbon, Nitrogen and Oxygen, A Critical Data Compilation (American Chemical Society, American Institute of Physics, New York, 1996).

${ }^{27}$ W. Demtröder, Laser Spectroscopy (Springer, Berlin, 1996).

${ }^{28}$ P. Macko, D. Romanini, and N. Sadeghi, Proceedings of Frontiers in Low Temperature Plasma Diagnostics IV, Rolduc, The Netherlands, March 2529, 2001

${ }^{29}$ NIST Chemistry Webbook, http://webbook.nist.gov/chemistry/

${ }^{30}$ D. Chastaing, P. L. James, I. R. Sims, and I. W. M. Smith, Phys. Chem. Chem. Phys. 1, 2247 (1999).

${ }^{31}$ M. R. Scholefield, J.-H. Choi, S. Goyal, and H. Reisler, Chem. Phys. Lett. 288, 487 (1998).

${ }^{32}$ R. Guadagnini, G. C. Schatz, and S. P. Walch, J. Phys. Chem. A 102, 5857 (1998).

${ }^{33}$ A. de Graaf, Ph.D. thesis, Eindhoven University of Technology, 2000; see http: //alexandria.tue.nl/extra2/200011593.pdf

${ }^{34}$ W. Jacob, Thin Solid Films 326, 1 (1998). 